\title{
Behavioral Intention Mechanism of Socially Sustainable Activities: Bioethanol Feedstock Production in Khon Kaen, Thailand
}

\author{
Sora $\mathrm{Yi}^{1} \&$ Masafumi Inoue ${ }^{2}$ \\ ${ }^{1}$ Department of Urban Planning, Daejeon Development Institute, Daejeon, South Korea \\ ${ }^{2}$ Asian Natural Environmental Science Center, The University of Tokyo, Tokyo, Japan \\ Correspondence: Sora Yi, Department of Urban Planning, Daejeon Development Institute, 85 Jungang-ro, \\ Jung-gu, Daejeon, 301-763, South Korea. Tel: 82-42-530-3524. E-mail: sora@djdi.re.kr
}

\author{
Received: August 5, 2013 Accepted: March 17, 2014 Online Published: April 16, 2014 \\ doi:10.5539/jsd.v7n3p35 URL: http://dx.doi.org/10.5539/jsd.v7n3p35
}

\begin{abstract}
Emerging concern over social implications of large-scale adoption is a motivation to require certification of the sustainable origins of biofuels. In terms of the feasibility of biofuel supply in Japan, this study examines the behavioral intentions of sustainable activities by using social criteria of international levels in the context of bioethanol feedstock production in Khon Kaen, Thailand. The models adapted from the theory of planned behavior were tested by using the structural equation model. The main results are as follows: (1) In terms of the perception of working rights and conditions, which was largely influenced by the "awareness: real conditions" and "awareness: real conditions for the participants' personal lives", "personal norm" indicated the highest score. (2) "Education" had the greatest impact on solutions for personal welfare and well-being with respect to sustainable activities. (3) The scores of the importance for social welfare and well-being included six categories: reasonable compensation, reasonable working hours, healthcare and safety, fair treatment of all workers, good communication, and education with the similar ranges of scores and regression weights. (4) The "attitude toward the behavior" was the most influential predictor of "behavioral intention". Results of this investigation give an implication to design a social criteria framework in agriculture activities such as the ethanol feedstock production.
\end{abstract}

Keywords: behavior modeling, theory of planned behavior, social criteria, bioethanol feedstock production

\section{Introduction}

In recent years, the global production and use of biofuels have increased dramatically because of increasing energy security concerns, environmental and social considerations, and the urgent need to revitalize rural communities. Sustainability criteria including environmental and social aspects would have a direct impact on international biofuel trade. However, the transformation of conventional farms into the fast-growing biofuel agribusiness has changed the income, employment, and quality of life of farming communities in affected rural areas, particularly those in developing countries. In addition, there has been growing concern over the social implications of large-scale adoption efforts as well as the health and well-being of those affected (IEA Bioenergy, 2005). This was a motivation to require certification, which is derived from many forms of the principles and criteria of the sustainable origins of biofuels as shown in Table 1 (eXtension, 2013).

Table 1. Definition of sustainability standards for biofuels

\begin{tabular}{|c|c|}
\hline & Definition \\
\hline Principle & $\begin{array}{l}\text { A concisely formulated guideline or rule, presented as a basis for reasoning or } \\
\text { action }\end{array}$ \\
\hline Criterion & Basically a defining feature that helps explain the meaning of a principle \\
\hline Indicator & $\begin{array}{l}\text { A measurable or observable feature that is used to test whether some criterion is } \\
\text { being met }\end{array}$ \\
\hline
\end{tabular}


The sustainability criteria considered in this paper have been adapted from the two social principles of the meta-standard approach suggested by Renewable Transport Fuel Obligation (RTFO) shown in Table 2 (RFTO, 2008): workers' rights and working relationships and land rights and community relations. These criteria were chosen because they were applicable at the international level. For the broader acceptance of social sustainability principles, it is necessary to consider both universal and local norms (Dreyer et al., 2006). However, few studies have examined how producers, particularly small-scale farmers, recognize sustainability principles or criteria and try to meet the goal of specific indicators and get the certification with respect to sustainability.

Table 2. Meta-standards approaches suggested by RTFO
Meta standards: seven principles
Environmental principles
1. Biomass production will not destroy or damage large above or below ground carbon stocks
2. Biomass production will not lead to the destruction or damage to high biodiversity areas
3. Biomass production does not lead to soil degradation
4. Biomass production does not lead to the contamination or depletion of water sources
5. Biomass production does not lead to air pollution
Social principles
6. Biomass production does not adversely affect workers rights and working relationships
7. Biomass production does not adversely affect existing land rights and community relations

Small-scale production and government-led management of sugarcane and cassava, which are the main feedstocks of bioethanol, have been implemented in Thailand. Currently, there are 47 ethanol plants with a total capacity of 12.3 million liters per day (there were 12 plants under construction as of 2010; the plants' total capacity was expected to be 2.6 million liters per day); these plants have been collecting sugarcane, molasses, and cassava from small-scale farmers in Thailand (DEDE, 2010a; DEDE, 2010b; DEDE, 2010c). Figure 1 indicates the big increases of bioethanol production in Thailand in recent years.

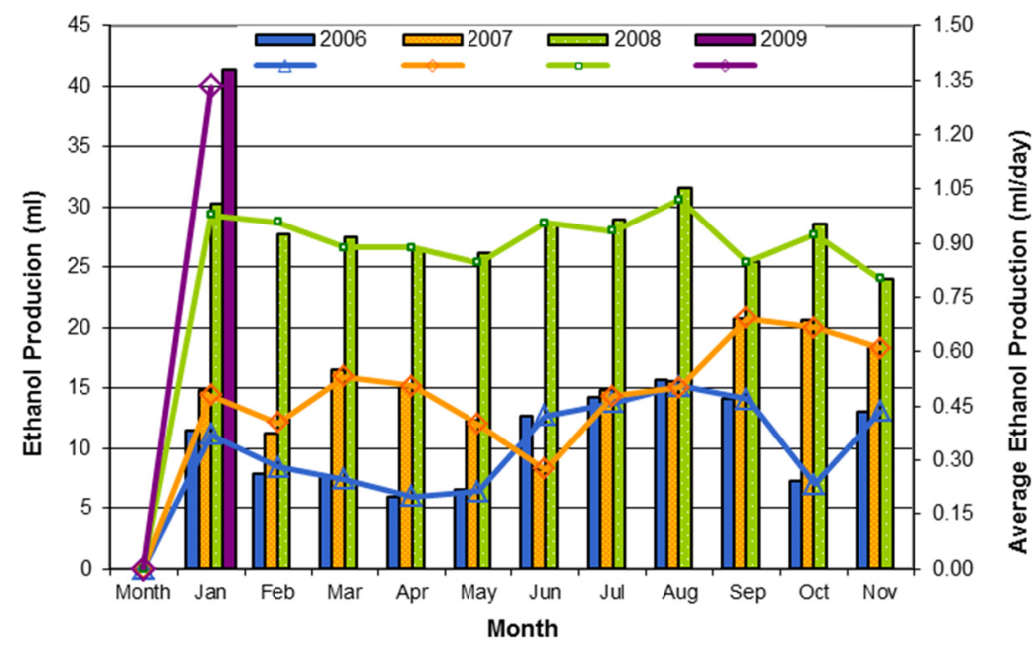

Figure 1. Amount of bioethanol production in Thailand

Note: Source from DEDE, 2010a.

The amount of production increased dramatically from 135 million liters in 2006 to 322 million liters in 2008 (DEDE, 2010a). In terms of cassava production, Thailand was the third biggest producer with 21.4 million tons (11\% of global production) in 2003 (DEDE, 2010d). Japan, because of its proximity, is expected to be one of the largest importers. In terms of the feasibility of biofuel supply in Japan, two types of feedstocks have been 
considered for bioethanol: sugarcane and cassava from Khon Kaen in Thailand, but sugarcane has been deemed to be the most desirable feedstocks for bioethanol because of its high yield per hectare harvested (APEC, 2008).

There has been growing concern about the behavioral model derived from psychological variables, that is, how an individual's beliefs and attitudes influence individual behavior. Taylor and Todd (1995) indicated that attitudes, intentions, situational factors, and perceptions are likely to be important predictors of sustainable activities. The theory of reasoned action (TRA), which was proposed by Martin Fishbein and Icek Ajzen in 1975 has proved to the most popular model explaining the mechanisms of attitudes toward actions, subjective norms, intentions, and behaviors. According to the TRA (Figure 2), if people evaluate the suggested behavior as positive (attitude) and if they believe that their significant others would want them to perform the behavior (subjective norm), they would be more likely to exhibit higher intentions (motivation) to do so. A high correlation of attitudes and subjective norms to behavioral intentions, and subsequently to behavior has been confirmed in many studies (Sheppard et al., 1988). Prior research has shown that people's behavior is strongly influenced by their confidence in their ability perform that behavior (Bandura et al., 1980). From this reason, Ajzen introduced the theory of planned behavior (TPB) in 1985 by adding a new component; that is, he added perceived behavioral control to TRA and modified the original TPB model by adding a new variable, actual behavioral control in 2002 (Ajzen, 2006). Perceived behavioral control, which originates from self-efficacy theory (Bandura, 1977), is an individual's perceived ease or difficulty of performing the particular behavior (Ajzen, 1988).

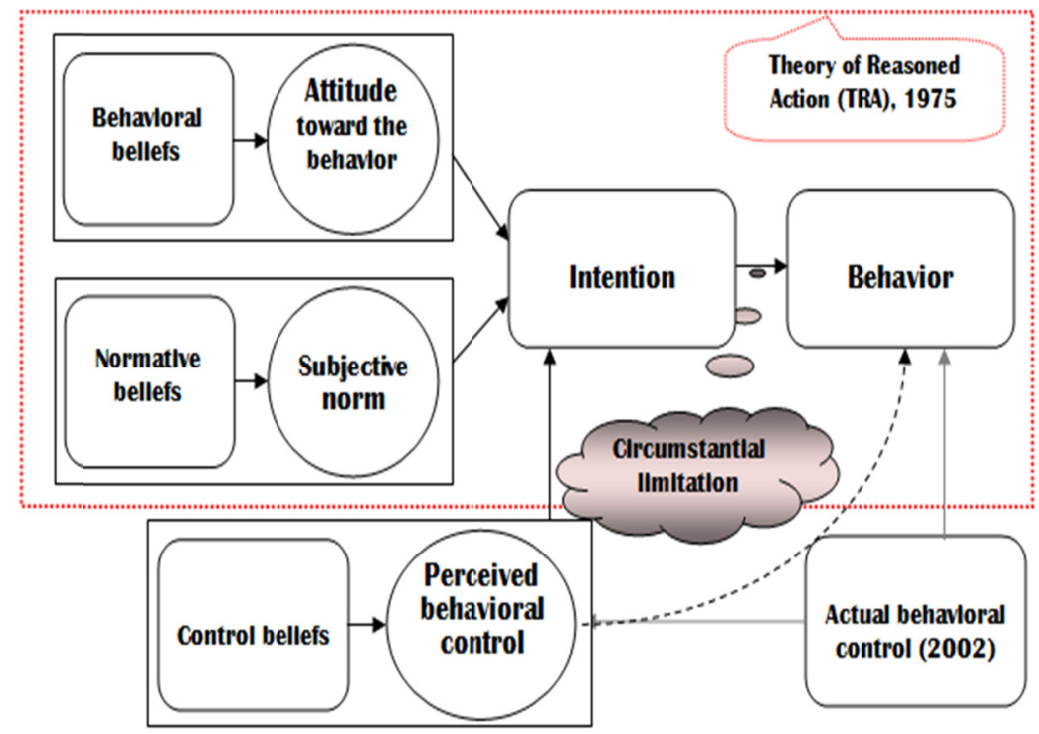

Figure 2. Theory of planned behavior model

In this regard, this study examines the behavioral intention mechanism of sustainable activities on social criteria, which has been adapted from the original TPB model, in the context of bioethanol feedstock production in Khon Kaen, Thailand.

\section{Methodology}

\subsection{Framework of Behavior Intention Modeling Based on Social Criteria}

The holistic framework of this study is presented in Figure 3. The research in Khon Kaen, Thailand, was organized into three main areas: a) an economic and behavioral evaluation of supply options between feedstock for food and that for bioethanol (Nakajima et al., 2010), b) perceptions and behavioral intentions with respect to environmental sustainability (Yi et al., 2010), and c) perceptions and behavioral intentions with respect to social sustainability. The last area was constructed and analyzed for this study. The participants (sugarcane or cassava farmers) in this survey were considered to be current or potential producers of bioethanol feedstock and were interviewed for all three areas of research on the same day. In hearing research of pre-survey, the participants perceived changes in their surroundings because of the expansion of bioethanol feedstock production and the need for proactive responses to economic, environmental, and social sustainability. 
From the perspective of sustainable agriculture practices, this model was tested using the structural equation model (SEM). SEM includes both confirmatory and exploratory modeling for testing and estimating causal relations using a combination of statistical data and qualitative causal assumptions (Pearl, 2000). Further, the models should be modified to obtain accepted models by establishing a link of error valuables. The outcome figures did not indicate the links of error valuables due to their complication, thus the results of links were addressed in the text of each section. Model fit was indicated as fit statistic results for Goodness of Fit Index (GFI), Comparative Fit Index (CFI), Root Mean Square Residual (RMR), and Root Mean Square Error of Approximation (RMSEA). The data set, which consisted of heads of agricultural households in Khon Kaen, was examined by taking a combined top-down and bottom-up approach. This combined approach was applied to investigate the factors influencing the perceptions of working rights and conditions, the solutions (sustainable activities) for personal welfare and well-being, and the importance of sustainability criteria in social welfare and quality of life. A principal component analysis (PCA) was conducted to choose possibly correlated factors, and all data were assessed by SPSS 20.0 and Amos 20.0.

The scores and weight regressions of perceptions, solutions, and importance were determined first, followed by an examination of the mechanism of behavioral intentions with respect to the items divided by PCA. The path analysis of this mechanism provided a theoretical framework for integrating weight regression (path coefficients) between the attitude toward behavior (AB), the subjective norm (SN), perceived behavior control (PBC), and the behavioral intention (I). The actual behavior could not be considered in the study because of the limitation to figure out the changes between past behavior and future behavior by this survey at once. These modified social models were used to investigate the most influential predictor of sustainable activities on social aspects in terms of bioethanol feedstock production and identify the driving force for improving sustainable behaviors.

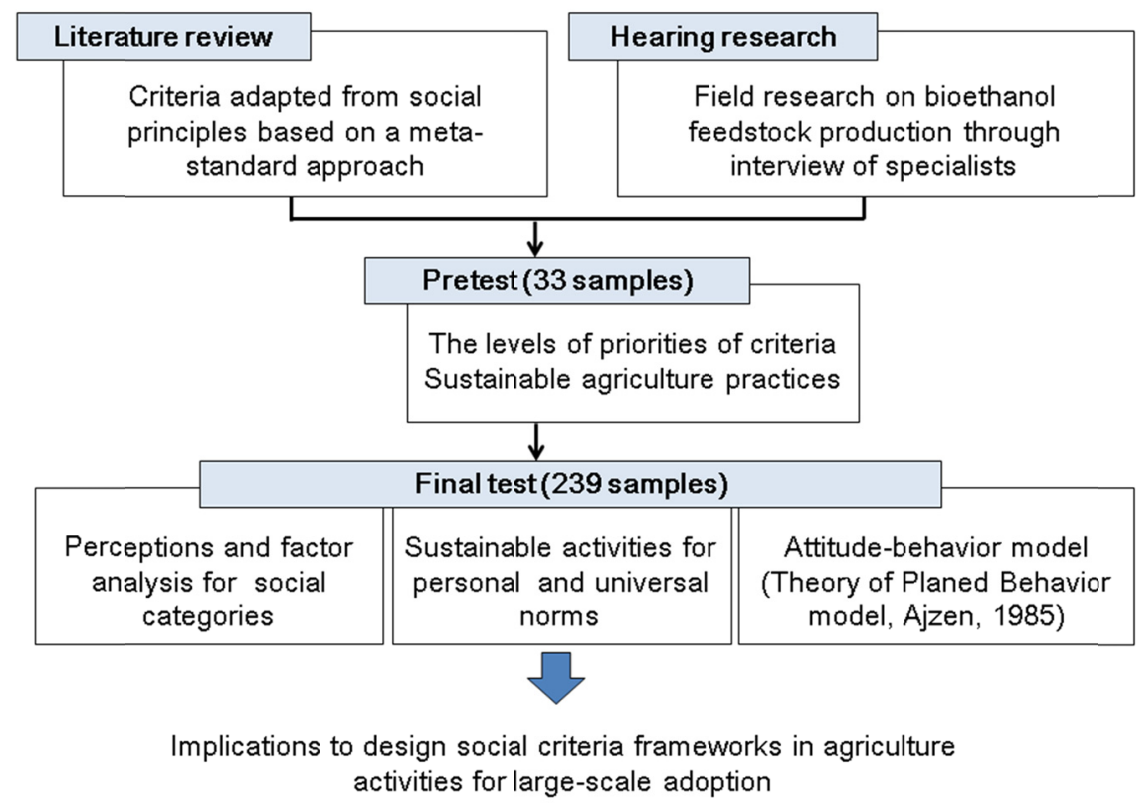

Figure 3. Holistic framework of this study

\subsection{Study Field and Questionnaire Structure}

Khon Kaen, a regional center for education, financial institutions, government offices, and transportation, is the second-largest province in the northeastern area of Thailand (Figure 4). Khon Kaen City has a population of 126,360 ; its density is 2,748 people per sq. $\mathrm{km}$ (Wong-Asa, 2006). There are two bioethanol plants with a total capacity of 280 thousand liters per day; the plants use cassava and sugarcane/molasses as feedstocks (DEDE, 2010c). 


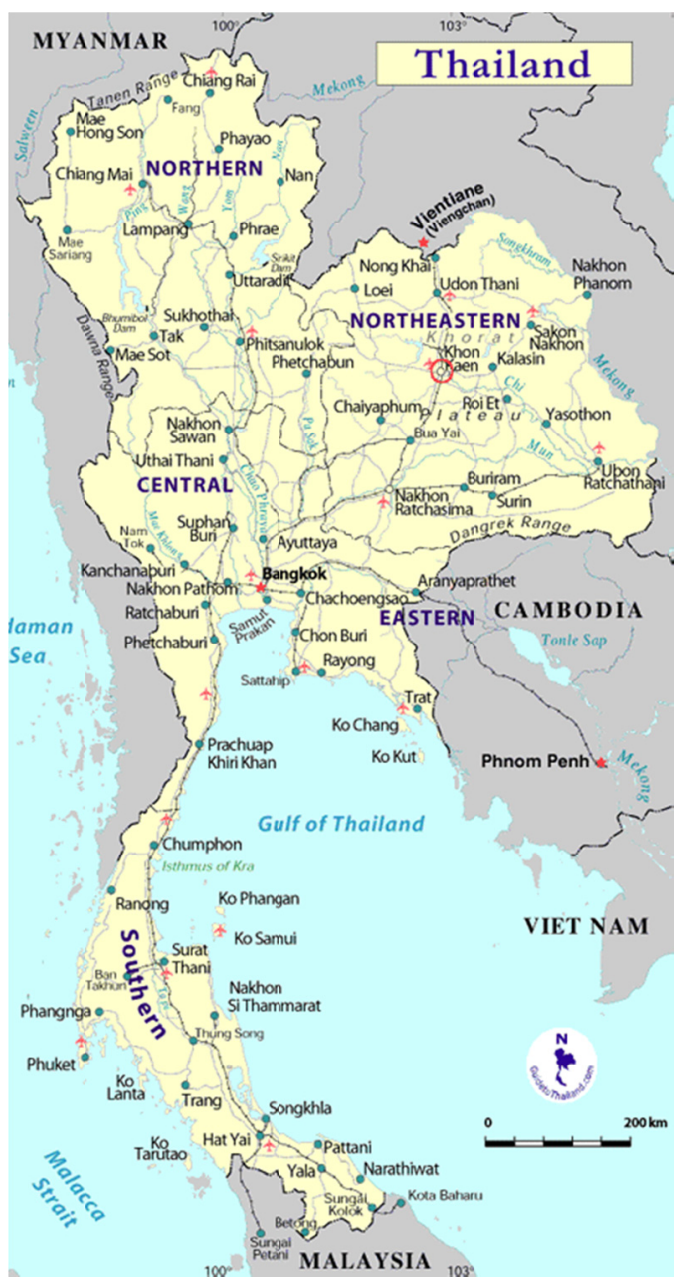

Figure 4. Khon Kaen, Thailand

Note: Source from KKU, 2011.

The questionnaire was in Thai; it was modified a number of times so that the respondents (farmers) could understand it easily. All survey data of this study were collected through personal interviews (the interviewers were supervised by Khon Kaen University). A pretest was conducted in August 2009. The pretest had 33 respondents (the number of respondents in the pretest was designed to be approximately $10 \%$ of the final survey). To ensure the statistical validity of the model, we tried to obtain at least 200 respondents; we obtained 239 respondents. The distribution of interview locations was designed to be proportional to the resident population.

Many aspects of agriculture management have been "gendered" in previous studies (Scheinberg et al., 1999). Women and men have been known to play different roles in agricultural practices and management at all levels. However, some households in Khon Kaen had customs reflecting a matriarchal society. With respect to encouragement for sustainable agricultural practices, this study requires a good understanding of head behavior within the household. Thus, an important criterion was the selection of the appropriate head of household; that is, who was responsible for feedstock (sugarcane or cassava) production.

The first portion of the survey addressed common issues, including general information regarding the farm and sugarcane or cassava production. The second portion addressed the perception and sustainable activities with respect to environmental (question numbers 1 92) and social (93 136) aspects. The 44 questions in the last portion investigated the social behavior model.

The first part of the social section assessed the perception of working rights and conditions (compensation, forced labor, and healthcare); this part was divided into the respondents' knowledge, awareness of real conditions in Khon Kaen, awareness of real conditions of welfare and well-being for respondents' personal lives, and personal norms. 
The second part investigated the solutions for personal welfare and well-being (quality of life and happiness), which were divided into good working conditions (reasonable compensation, reasonable working hours, and provision of water and food), minimal use of chemicals (minimal use of chemical fertilizers and pesticides for health reasons), communication (listening and discussing to solve conflicts), and education (providing advice on good working conditions and well-being).

The third part investigated the importance for social welfare and well-being, which was divided into six categories: reasonable compensation, reasonable working hours, healthcare and safety, fair treatment of all workers, good communication, and education.

The forth part estimated the behavioral intention mechanisms regarding the six categories (the underlined phrases were replaced with each of the six categories), which were composed of four variables: AB (e.g., What I give agreed-upon pay/reasonable compensation in time to workers in my farm is good/bad), SN (My family or friends think that I should give agreed-upon pay/reasonable compensation in time to workers in my farm), PBC $(\mathrm{PBC} 1=$ Actually, What I give agreed-upon pay/reasonable compensation in time to workers in my farm is difficult/easy; $\mathrm{PBC} 2=$ Whether I give agreed-upon pay/reasonable compensation in time to workers in my farm is entirely up to me), and I (I try to give agreed-upon pay/reasonable compensation in time to workers in my farm). The six categories were adopted from the previous analysis of the importance of social welfare and well-being; the categories were modified (by hearing research and a pretest) so that they could be easily understood by the respondents (farmers in Khon Kaen). The questionnaire of this part was constructed based on the TPB questionnaire instruction (Ajzen, 2006). The hypothesis of this model is that the three core variables, $\mathrm{AB}, \mathrm{SN}$, and $\mathrm{PBC}$, can collectively explain a statistically significant amount of variance in I for sustainable activities in feedstock production. The questions were constructed in the order of I, AB, SN, PBC1, and PBC2.

A seven-point Likert scale was used for the answers (strongly no/bad=1, quite no/bad=2, slightly no/bad=3, neither $=4$, slightly yes/good $=5$, quite yes $/$ good $=6$, and strongly yes/good $=7$ ).

\section{Results and Discussions}

\subsection{Descriptive Statistics}

Table 3. Socio-demographic characteristics of the respondents

\begin{tabular}{|c|c|c|}
\hline Characteristics & Distribution of answers & Notes \\
\hline Sample number & $\begin{array}{l}239 \\
\text { (sugarcane: } 126 \text { and cassava: 113) }\end{array}$ & \\
\hline Gender & Male: $83.3 \%$; Female: $16.7 \%$ & \\
\hline Age & $\begin{array}{l}\text { 20s: } 1.3 \% ; 30 \mathrm{~s}: 10.5 \% ; 40 \mathrm{~s}: 28.0 \% \text {; } 50 \mathrm{~s}: 33.5 \% \text {; } \\
\text { over } 60: 26.7 \%\end{array}$ & $\begin{array}{l}\text { Mean/Standard deviation: } \\
52.7 / 0.76 \\
\text { (Range 25 87) }\end{array}$ \\
\hline Marital status & $\begin{array}{l}\text { Married: } 88.3 \% \text {; Single: } 4.2 \% \text {; Widow: } 1.7 \% \text {; } \\
\text { Divorced: } 0.4 \% \text {; Other: } 5.4 \%\end{array}$ & \\
\hline Educational level & $\begin{array}{l}\text { Elementary: } 82.4 \% \text {; Junior high school: } 7.9 \% \text {; High } \\
\text { school: } 5.9 \% \text {; Vocational: } 2.5 \% \text {; College: } 0.8 \% \text {; } \\
\text { Other: } 0.4 \%\end{array}$ & \\
\hline $\begin{array}{l}\text { Work frequency } \\
\text { (farm) }\end{array}$ & Daily: $69.9 \%$; Sometimes: $26.8 \%$; Never: $3.3 \%$ & \\
\hline $\begin{array}{l}\text { Household income } \\
\text { per year }\end{array}$ & $\begin{array}{l}\text { 210 999 USD: } 12.1 \% ; 1000 \sim 1999 \text { USD: 32.2\%; } \\
\text { 2000 2999 USD: 15.5\%; 3000 3999 USD: 11.7\%; } \\
\text { 4000 4999: 5.4\%; Over 5000 USD: } 23.0 \%\end{array}$ & $\begin{array}{l}\text { Mean/Standard deviation: } \\
3683 \text { USD / } 219.97 \\
\text { (Range: } 210 \sim 32100 ; 2781 \\
\text { USD from agriculture and } 902 \\
\text { USD from other sources) }\end{array}$ \\
\hline
\end{tabular}

Note: USD recalculated from THB, the original unit (100 Baht to 3 USD). 
Socio-demographic characteristics of the respondents (one individual per household), along with some household features, are summarized in Table 3. According to the one-way Analysis of Variance (ANOVA) results, there were no correlations (Levene's Test for Equality of Variances $\mathrm{F} \geq 1$ ) between gender and the educational level (F 7.599 and Sig 0.006), gender and work frequency (F 5.140 and Sig 0.024), and work frequency and household income (F 2.313 and Sig 0.130).

\subsection{Perception of Working Rights and Conditions}

In terms of the perception of working rights conditions, "personal norm" indicated the highest score (Figure 5). The hypothetical model for the perception of working rights and conditions was based on the factors chosen from PCA (KMO MSA 0.719, good adequacy) in Table 4; it was further modified to establish a link of error valuables between "knowledge" and "personal norm" (Figure 6). The variance was also modified from - 0.462 to 0.005 because the variance of error valuable for "awareness: real condition in Khon Kaen" was negative. The modified model indicated that the perception was influenced the most by the "awareness: real condition in Khon Kaen" (regression weight: 1.00) and the least by "personal norm" (regression weight: 0.01). This implies that even if the current average score for the "awareness: real condition in Khon Kaen" is the lowest, the perception of working rights and conditions can be changed dramatically by changes in the real conditions of Khon Kaen in future.

Table 4. Factors chosen from PCA

\begin{tabular}{lccc}
\hline \multicolumn{1}{c}{ Rotated Component Matrix } & \multicolumn{3}{c}{ Component } \\
\cline { 2 - 4 } & 1 & 2 & 3 \\
\hline $\begin{array}{l}\text { Knowledge: I know the meaning of "working conditions (wage, forced labor, and } \\
\text { healthcare)". }\end{array}$ & 0.090 & 0.985 & 0.119 \\
$\begin{array}{l}\text { Awareness (Real condition in Khon Kaen): I think that "working condition (wage, } \\
\text { forced labor, and healthcare) in the farm is bad in my village". }\end{array}$ & 0.155 & -0.062 \\
$\begin{array}{l}\text { Awareness (Real condition for my well-being): I think that "working condition (wage, } \\
\text { forced labor, and healthcare) in the farm gives damages to my welfare and well-being } \\
\text { (quality of life and happiness)". }\end{array}$ & -0.012 & 0.095 \\
$\begin{array}{l}\text { Personal norm: I think that "good working condition (reasonable wage, reasonable } \\
\text { working hours, and providing water and food) will help my welfare and well-being } \\
\text { (quality of life and happiness)". }\end{array}$ & & & \\
\hline
\end{tabular}

Note: a. Rotation converged in 4 iterations.

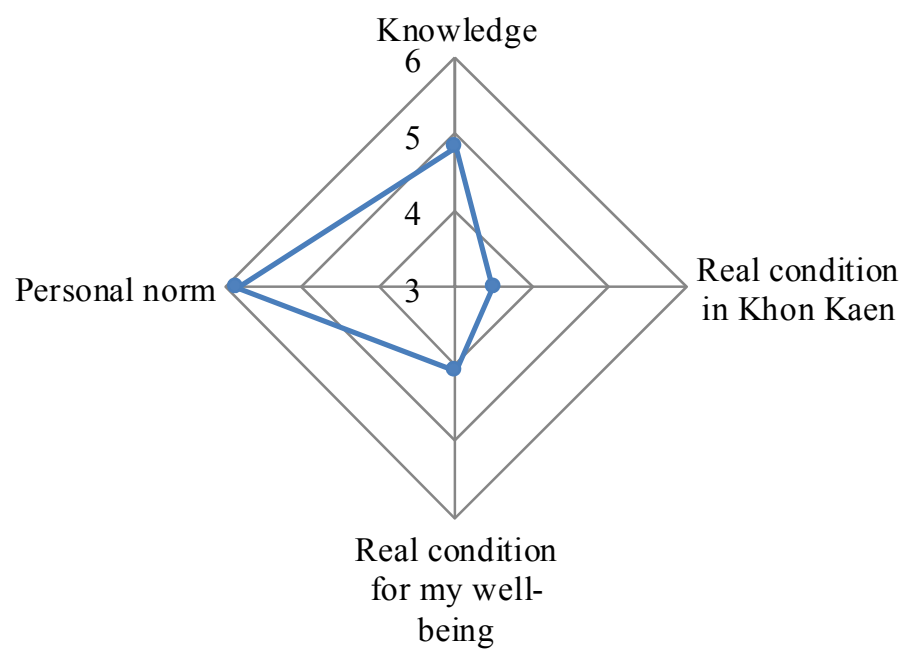

Figure 5. Scores of the modified model for perception 


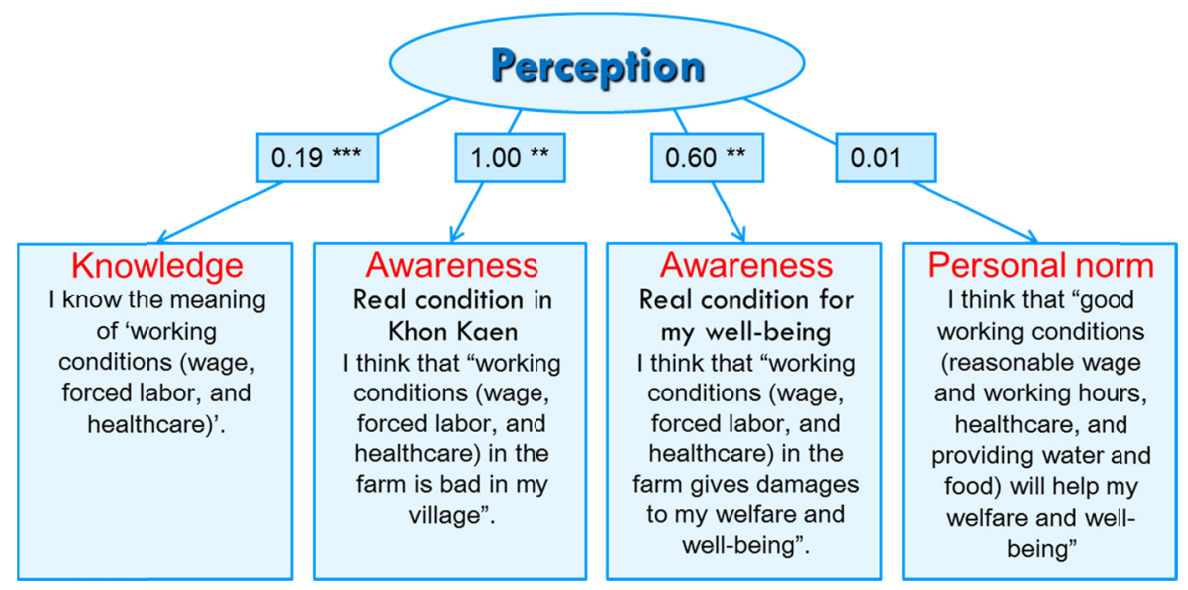

Figure 6. Standard estimates of the modified model for perception

Note: ${ }^{*} \mathrm{p}<0.05, * * \mathrm{p}<0.01, * * * \mathrm{p}<0.001$.

Chi-square 2.061, DF 2, P 0.357 (acceptable model), GFI 0.996 (very good fit), CFI 1.000 (perfect fit), RMR 0.039 (good fit), and RMSEA 0.011 (good fit).

\subsection{Solutions for Personal Welfare and Well-Being}

The categories of solutions for personal welfare and well-being were adapted from the meta-standard approach suggested by RTFO. These categories were chosen because they were applicable at the international level, and they were verified through a pretest survey (a combined top-down and bottom-up approach).

This part introduced a subjective question to the solutions for "my welfare and well-being (quality of life and happiness)" and deducted an additive category "Education on good working conditions and well-being" from various answers. The scores of each category were similar, with a range between 5.79 and 6.09 (Figure 7). The hypothetical model of solutions was accepted without any modification. Out of the four categories, "education" (Figure 8) had the greatest impact on the solutions for personal welfare and well-being (regression weight=0.74), followed by "good communication", "less chemicals", and "good working conditions".

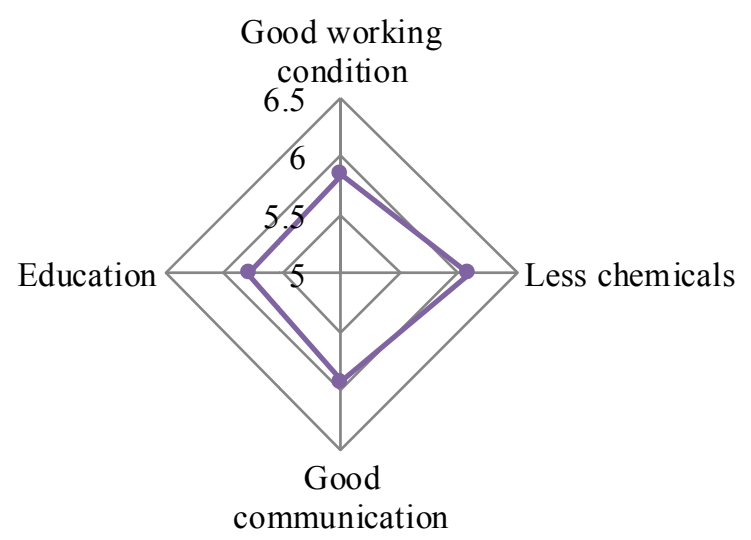

Figure 7. Scores of the hypothetical model for solution 


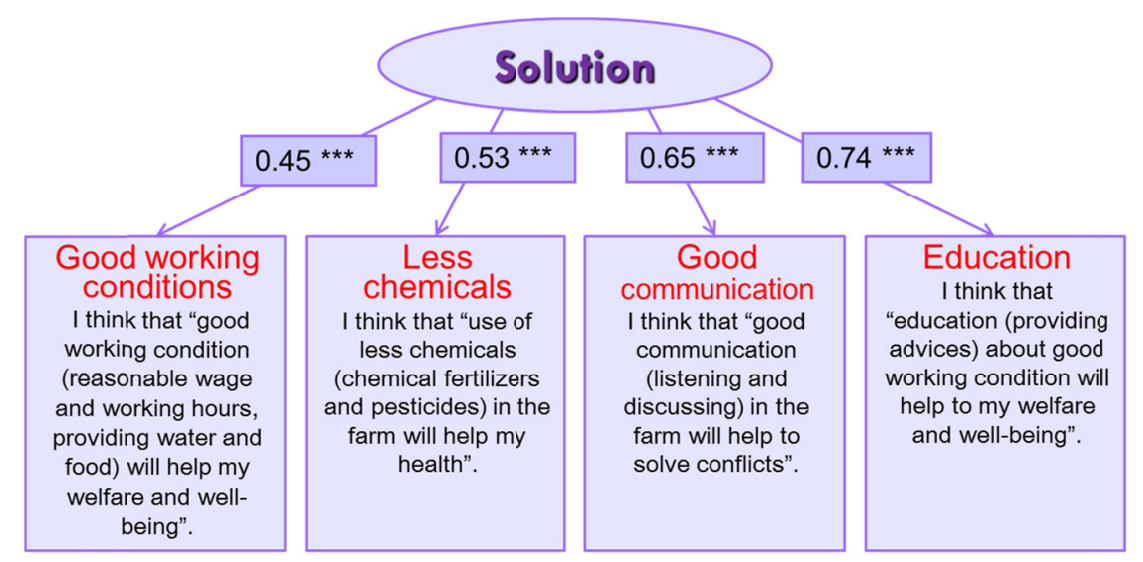

Figure 8. Standard estimates of the hypothetical model for solution

Note. ${ }^{*} \mathrm{p}<0.05, * * \mathrm{p}<0.01, * * * \mathrm{p}<0.001$.

Chi-square 3.017, DF 2, P 0.221 (acceptable model), GFI 0.994 (very good fit), CFI 0.993 (very good fit), RMR 0.020 (good fit), and RMSEA 0.046 (good fit).

\subsection{Importance for Social Welfare and Well-Being}

The scores of each category were very similar, with a range between 5.97 and 6.09 (Figure 9). The hypothetical model of the importance of social welfare and well-being was modified to establish links of error valuables between "reasonable compensation" and "reasonable working hours", "reasonable compensation" and "Healthcare and safety", and "good communication" and "education". Out of the six categories, "fair treatment of all workers" (Figure 10) had the greatest impact on importance (regression weight $=0.85$ ). The regression weights of other categories fell within a range between 0.59 and 0.70 .

The levels of scores based on personal and universal norms increased slightly from personal welfare and well-being (average 5.91) to social welfare and well-being (average 6.04).

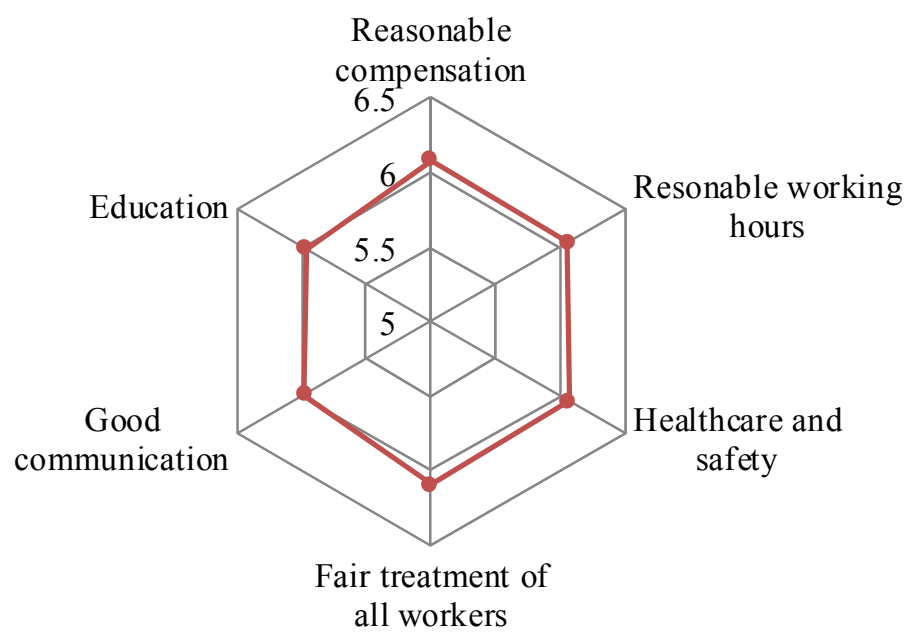

Figure 9. Scores of the modified model for importance 


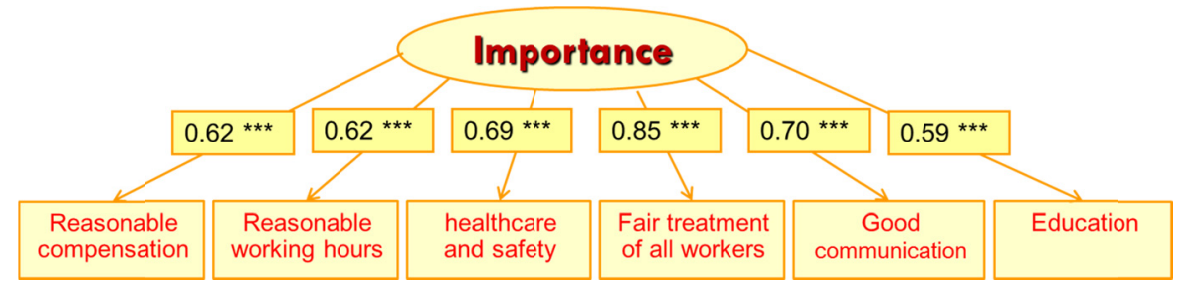

Figure 10. Standard estimates of the modified model for importance

Note. ${ }^{*} \mathrm{p}<0.05, * * \mathrm{p}<0.01,{ }^{* * *} \mathrm{p}<0.001$.

Chi-square 6.917, DF 6, P 0.329 (acceptable model), GFI 0.990 (very good fit), CFI 0.998 (very good fit), RMR 0.017 (good fit), and RMSEA 0.025 (good fit).

\subsection{Behavioral Intention Mechanisms}

The construction of every question was repeated for the five types (refer to 2.2) of observed (measured) variables: $\mathrm{AB}, \mathrm{SN}, \mathrm{PBC} 1, \mathrm{PBC} 2$, and I. The following numbers indicate the number for each of the six categories: $1=$ agreed-upon pay (reasonable compensation), 2=no excessive work hours (reasonable working hours and no forced labor), $3=$ healthcare and safety (taking care of workers, including potable drinking water, clean toilettes, clean place to eat, and accessible medical care), $4=$ fair treatment of all workers, $5=$ communication (listening and discussing to solve conflicts), and 6=education (providing advice) on good working conditions and well-being of all workers.

As shown in Figure 11, the scores of the six categories indicated that "1= agreed-upon pay" (i.e., AB1, SN1, P11, and I1) had the highest scores (a range between 5.51 and 6.32). The averages of the five types of variables indicated that $\mathrm{AB}$ had the highest score (6.08), followed by SN, I, PBC1, and PBC2.

The holistic hypothetical model (see Figure 12, this figure omitted correlational links between $\mathrm{AB}$ and $\mathrm{SN}, \mathrm{AB}$ and $\mathrm{PBC} 1, \mathrm{AB}$ and $\mathrm{PBC} 2, \mathrm{SN}$ and $\mathrm{PBC} 1$, and $\mathrm{SN}$ and $\mathrm{PBC} 2$ ) of behavioral intention mechanisms, which were composed of AB, SN, PBC (1 and 2), and I, was modified and divided into three items through PCA (KMO MSA 0.907, very good adequacy). The data of PBC1 were excluded from the modified model because they caused a high level of chi-square, which was verified by the sample number (239) over Hoelter's critical N ( $=102$ at the $5 \%$ significant level).

The three items were named as follows: "working Rights and Conditions" (RC, including two categories: 1=pay and $2=$ =work hours), "Welfare and Communication" (WC, including three categories: $3=$ healthcare and safety, $4=$ fair treatment, and $5=$ communication), and "Education and self-Improvement" (EI, including one category: $6=$ education).

The hypothetical model of RC required the correlational relationships among three exogenous latent variables (i.e., AB, SN, and PBC2). This model was modified to establish links between e2 and e8, e2 and e26, and e8 and e26. The modified model was accepted: chi-square 7.832, DF 11, P 0.728 (acceptable model), GFI 0.992 (very good fit), CFI 1.000 (perfect fit), RMR 0.028 (good fit), and RMSEA 0.000 (perfect fit). Out of the three exogenous latent variables, $\mathrm{AB}$ had the greatest impact on the endogenous latent variable, I (regression weight/path coefficient $=0.47)$, and the other variables, SN (0.38) and PBC2 (0.06), had relatively weak effects on I. Out of the two categories (1=pay and $2=$ work hours), pay had a greater effect on RC than work hours (Table 5).

The hypothetical model of WC was modified to establish links with the three exogenous latent variables (i.e., $\mathrm{AB}, \mathrm{SN}$, and PBC2). This model required links between e3 and e9, e3 and e27, e5 and e28, e9 and e27, e11 and e28, e21 and e27, and e22 and e29. The modified model was accepted: chi-square 46.119, DF 42, P 0.306 (acceptable model), GFI 0.968 (very good fit), CFI 0.997 (very good fit), RMR 0.034 (good fit), and RMSEA 0.020 (good fit). Out of the three exogenous latent variables, $\mathrm{AB}$ had the greatest impact on I (regression weight/path coefficient=1.00), followed by SN (0.002) and PBC2 (-0.02). Out of the three categories ( $3=$ healthcare and safety, $4=$ fair treatment, and $5=$ communication), fair treatment affected $\mathrm{WC}$ the most (Table $5)$.

The hypothetical model of EI consisted of three exogenous observed variables (i.e., AB6, SN6, and P26, see Figure 12) as predictors of an observed endogenous variable (I6). This model required links between e6 and e12, e12 and e24, and e6 and e24. Out of the modified models, this final model was accepted with the lowest AIC (from 109.098 to 20.000) and the highest AGFI (from 0.448 to 1.000), indicating a perfect model (chi-square 
0.000, DF 0, P 0.000, GFI 1.000 CFI 1.000, and RMR 0.000). The hypothetical model of EI might have caused the high chi-square value by the sample number (239) over Hoelter's critical N ( $=20$ at the $5 \%$ significant level). Out of the three exogenous observed variables, AB6 had the greatest impact on I6 (regression weight/path coefficient $=0.42)$, followed by SN6 $(0.25)$ and P26 (0.15).

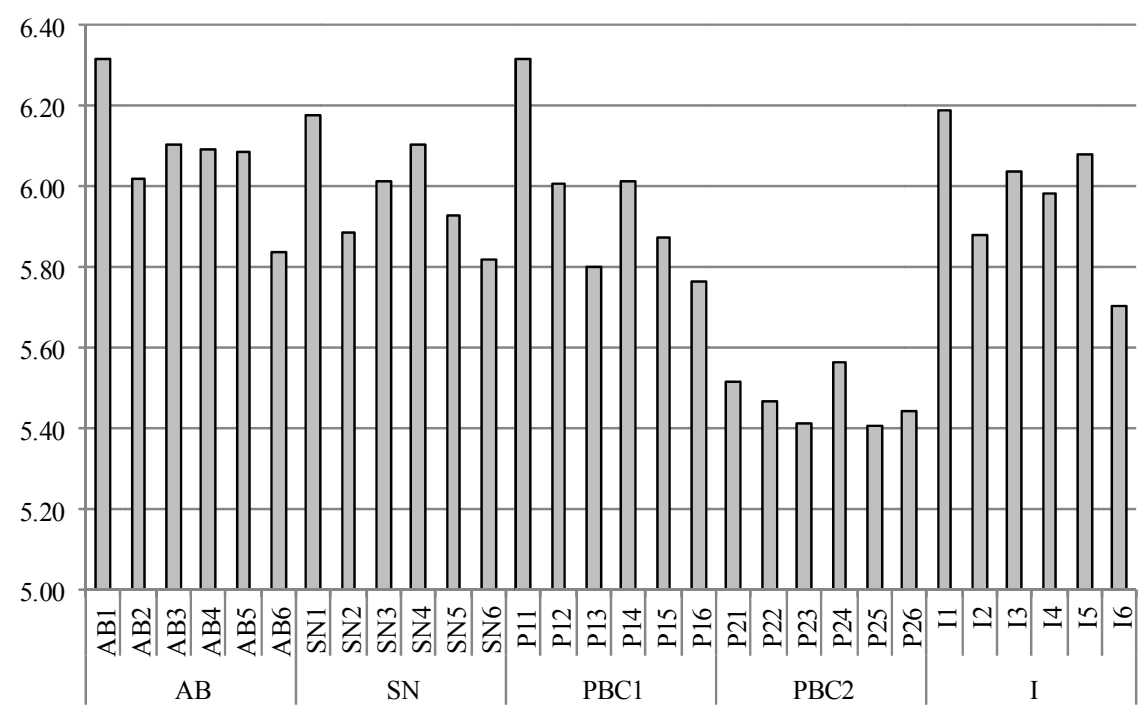

Figure 11. Scores of the five types of observed variables with respect to the six categories

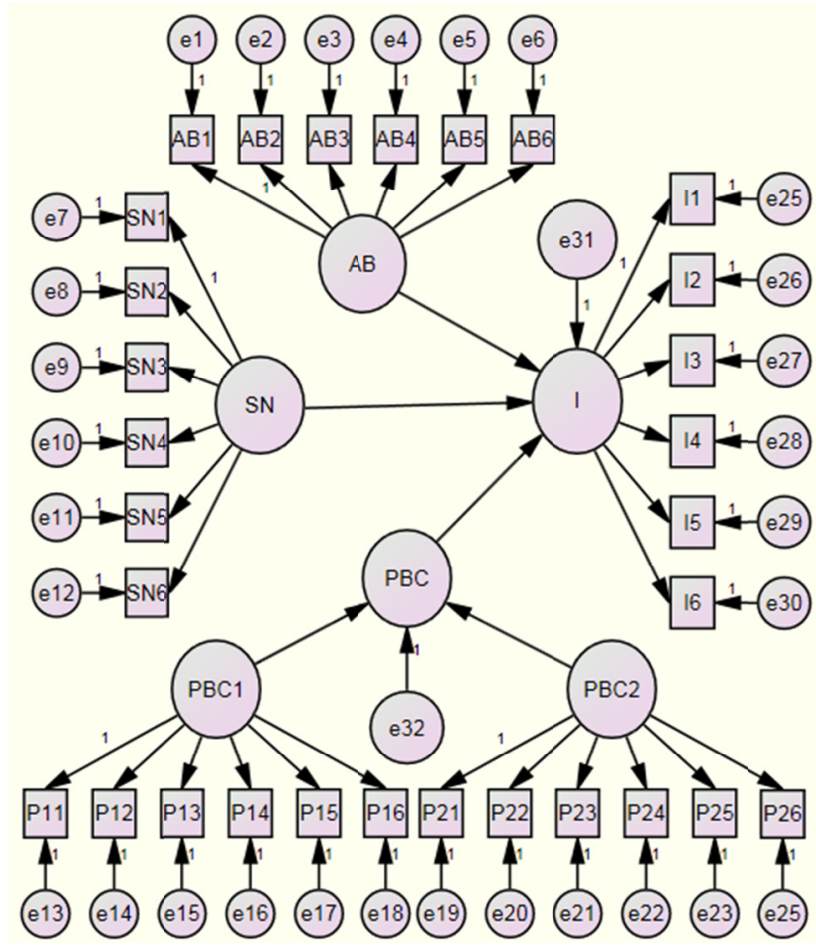

Figure 12. Holistic hypothetical model adapted from the TPB model 
Table 5. Standard estimates (regression weight) for behavioral intention models

\begin{tabular}{|c|c|c|c|}
\hline & $\mathrm{RC}$ & $\mathrm{WC}$ & EI \\
\hline SEM fitness criterion & Very good fitness & Very good fitness & Perfect model \\
\hline $\mathrm{AB}=>\mathrm{I}$ & $0.47 * *$ & $1.00 * * *$ & $0.42 * * *$ \\
\hline $\mathrm{SN}=>\mathrm{I}$ & $0.38 *$ & 0.002 & $0.25 * * *$ \\
\hline $\mathrm{PBC} 2=>\mathrm{I}$ & 0.06 & -0.02 & $0.15 * *$ \\
\hline Main category & Pay & Fair treatment & (Education) \\
\hline \multirow[t]{3}{*}{$\mathrm{AB}$} & $\Rightarrow$ AB1: $0.82 * * *$ & $\Rightarrow$ AB3: $0.64 * * *$ & No latent valuables \\
\hline & $\Rightarrow$ AB2: $0.62 * * *$ & $\Rightarrow$ AB4: $0.77 * * *$ & \\
\hline & & $=>$ AB5: $0.79 * * *$ & \\
\hline \multirow[t]{3}{*}{$\mathrm{SN}$} & $=>$ SN1: $0.78 * * *$ & $=>$ SN3: $0.64 * * *$ & \\
\hline & $=>$ SN2: $0.57 * * *$ & $=>$ SN4: $0.72 * * *$ & \\
\hline & & $=>$ SN5: $0.73 * * *$ & \\
\hline \multirow[t]{3}{*}{$\mathrm{PBC} 2$} & $=>$ P21: $0.99 * * *$ & $=>$ P23: $0.79 * * *$ & \\
\hline & $=>$ P22: $0.79 * * *$ & $=>$ P24: $0.89 * * *$ & \\
\hline & & $=>$ P25: $0.83 * * *$ & \\
\hline \multirow[t]{3}{*}{ I } & $=>\mathrm{I} 1: 0.96 * * *$ & $\Rightarrow$ I3: $0.59 * * *$ & \\
\hline & $=>\mathrm{I} 2: 0.39 * * *$ & $\Rightarrow$ I4: $0.81 * * *$ & \\
\hline & & $\Rightarrow$ I5: $0.69 * * *$ & \\
\hline
\end{tabular}

Note. ${ }^{*} \mathrm{p}<0.05,{ }^{* *} \mathrm{p}<0.01,{ }^{* * *} \mathrm{p}<0.001$.

\section{Conclusions}

The generalizability of the holistic behavioral intention mechanisms for sustainable activities on social aspects is limited. The modified structure equation models indicated that the attitude (AB) was the main predictor and that perceived behavior control (PBC2) had a weak effect on the intention (I). This indicates that because the intention (the amount of effort one is willing to exert to attain a goal, Ajzen, 1991) was closely linked to the respondents' attitudes, sustainable behaviors regarding social aspects are likely to be influenced by the willingness (behavioral intentions) of farmers. This also suggests that the promotion of sustainable activities should focus on attitudes toward behavior. In further study, these attitudes (individual favor) can be identified by driving forces, e.g. perceptions, solutions, and importance of social issues, which lead to increases in the scores of attitudes.

The results of this combined top-down and bottom-up approach imply that international standards can be applied to solve both personal and social welfare and well-being. Recognition of international standards relating to biofuel feedstock producers should be a criterion of acceptable management, and effective respect for social indicators. The results have implications for designing frameworks of social criteria for biofuel feedstock production, internationally acceptable social criteria, and certification in sustainable feedstocks of biofuels.

The results of the pre-survey indicate that the participants, who were interviewed as current or potential producers of bioethanol feedstock, perceived the need for proactive responses to economic, environmental, and social sustainability because of the expansion of bioethanol feedstock production. Thus, this indicates that the results for the behavioral intention mechanism cannot be generalized to various types of agricultural activities. Future research should examine the relationship between sustainable behavior and the impact of the feedstock price in Khon Kaen.

Further research had already been finished to investigate the behavioral intention model of environmental aspects using the structural equation model (SEM). In addition, the comparisons of the behavioral intention model based on both of environmental and social sustainability have been discussed (Yi, 2010). 


\section{Acknowledgments}

This project was supported by the New Energy and Industrial Technology Development Organization (NEDO) in Japan and Khon Kaen University in Thailand.

\section{References}

APEC. (2008). Survey of Biomass Resource Assessments and Assessment Capabilities in APEC Economies. Asia-Pacific Economic Cooperation. Retrieved from http://www.nrel.gov/docs/fy09osti/43710.pdf

Ajzen, I. (1988). Attitudes, personality, and behavior. Chicago: Dorsey Press.

Ajzen, I. (1991). The theory of planned behavior. Organization Behavior and Human Decision Processes, 50(2), 179-211. http://dx.doi.org/10.1016/0749-5978(91)90020-T

Ajzen, I. (2006). Constructing a TpB Questionnaire: Conceptual and Methodological Considerations. Ajzen official website. Retrieved from http://www-unix.oit.umass.edu/ aizen/pdf/tpb.measurement.pdf

Bandura, A. (1977). Self-Efficiency: Towards a unifying theory of behavior change. Psychological Review, 84, 199-215. http://dx.doi.org/10.1016/0146-6402(78)90002-4

Bandura, A., Adams, N. E., Hardy, A. B., \& Howells, G. N. (1980). Tests of the generality of self-efficacy theory. Cognitive Theory and Research, 4, 39-66. http://dx.doi.org/10.1007/BF01173354

DEDE. (2010a). List of Ethanol Plants with Construction Permit by Region. Department of Alternative Energy Development and Efficiency (DEDE) Ministry of Energy website. Retrieved from http://www.dede.go.th/dede/index.php?id=1003

DEDE. (2010b). List of Ethanol Plants under Construction. Department of Alternative Energy Development and Efficiency (DEDE) Ministry of Energy website. Retrieved from http://www.dede.go.th/dede/index.php?id=1003

DEDE. (2010c). Ethanol Production 2006-2009. Department of Alternative Energy Development and Efficiency (DEDE) Ministry of Energy website. Retrieved from http://www.dede.go.th/dede/index.php?id=1003

DEDE. (2010d). Supply, Demand and Types of Feedstock for Ethanol Production. Department of Alternative Energy Development and Efficiency (DEDE) Ministry of Energy website. Retrieved from http://www.dede.go.th/dede/index.php?id=1003

Dreyer, L. C., Hauschild, M. Z., \& Schierbeck, J. (2006). A Framework for Social Life Cycle Impact Assessment. International Journal of Life Cycle Assessment, 11(2), 88-97. http://dx.doi.org/10.1065/lca2005.08.223

eXtension. (2013). Sustainability Standards for Farm Energy. eXtension (an educational partnership of 74 universities in the United States). Retrieved from $\mathrm{http} / / /$ www.extension.org/pages/Sustainability_Standards_for_Farm_Energy

IEA Bioenergy. (2005). TASK 29 Socio-Economic Drivers in Implementing Bioenergy Projects. The International Energy Agency. Retrieved from http://www.task29.net/assets/files/Work_Programme_2006_2008.pdf

KKU. (2011). Khon Kaen University official website. Retrieved from http://www2.kku.ac.th/eng/mapthailand.htm

Nakajima, S., Yi, S., Krasuaythong, T., Pakdee, P., Nakashima, S., \& Inoue, M. (2010). Causative factors for formulating relationship between famers and bioethanol plants: Application of a structural equation model. Renewable Energy 2010: International Conference, 27 June - 2 July 2010, Yokohama, Japan.

Pearl, J. (2000). Causality: Models, Reasoning, and Inference. Cambridge University Press. ISBN 0-521-77362-8.

RTFO. (2008). Carbon and Sustainability Reporting Within the Renewable Transport Fuel Obligation Requirements and Guidance. Government Recommendation to RTFO Administrator.

Scheinberg, A., Muller, M., \& Evganie, L. T. (1999). Gender and Waste UNEP. Working Document 12, 1999.

Sheppard, B. H., Hartwick, J., \& Warshaw, P. R. (1988). The Theory of Reasoned Action: A meta-analysis of past research with recommendations for modifications and future research. Journal of Consumer Research, 15(3), 325-343. http://dx.doi.org/10.1086/209170

Taylor, S., \& Todd, P. (1995). Decomposition and crossover effects in the theory of planned behavior: A study of consumer adoption intentions. International Journal of Research in Marketing, 12(2), 137-155. http://dx.doi.org/10.1016/0167-8116(94)00019-K 
Wong-Asa, T. (2006). City Report of Khon Kaen. AUICK (Asian Urban Information Center of Kobe) First 2006 Workshop. Retrieved from www.auick.org/database/...1/.../WS2006-1CR-KhonKaen.pdf

Yi, S., Inoue, M., Nakajima, S., \& Nakashima, S. (2010). Perception and sustainable action on environmental criteria: An application to bioethanol feedstock production. Renewable Energy 2010: International Conference, July 2010, Yokohama, Japan.

\section{Copyrights}

Copyright for this article is retained by the author(s), with first publication rights granted to the journal.

This is an open-access article distributed under the terms and conditions of the Creative Commons Attribution license (http://creativecommons.org/licenses/by/3.0/). 